University of Nebraska - Lincoln

DigitalCommons@University of Nebraska - Lincoln

Faculty Publications from the Harold W. Manter Laboratory of Parasitology

2009

\title{
Acanthocephala from Amphibians in China with the Description of a New Species of Pseudoacanthocephalus (Echinorhynchida)
}

\author{
Sarah E. Bush \\ University of Kansas, bush@biology.utah.edu \\ Donald W. Duszynski \\ University of New Mexico, eimeria@unm.edu \\ Brent B. Nickol \\ University of Nebraska - Lincoln, bnickol1@unl.edu
}

Follow this and additional works at: https://digitalcommons.unl.edu/parasitologyfacpubs

Part of the Parasitology Commons

Bush, Sarah E.; Duszynski, Donald W.; and Nickol, Brent B., "Acanthocephala from Amphibians in China with the Description of a New Species of Pseudoacanthocephalus (Echinorhynchida)" (2009). Faculty Publications from the Harold W. Manter Laboratory of Parasitology. 127.

https://digitalcommons.unl.edu/parasitologyfacpubs/127

This Article is brought to you for free and open access by the Parasitology, Harold W. Manter Laboratory of at DigitalCommons@University of Nebraska - Lincoln. It has been accepted for inclusion in Faculty Publications from the Harold W. Manter Laboratory of Parasitology by an authorized administrator of DigitalCommons@University of Nebraska - Lincoln. 


\title{
ACANTHOCEPHALA FROM AMPHIBIANS IN CHINA WITH THE DESCRIPTION OF A NEW SPECIES OF PSEUDOACANTHOCEPHALUS (ECHINORHYNCHIDA)
}

\author{
Sarah E. Bush, Donald W. Duszynski*, and Brent B. Nickol† \\ Biodiversity Institute, University of Kansas, Lawrence, Kansas 66045. e-mail: bush@biology.utah.edu
}

\begin{abstract}
Amphibians of 24 species were surveyed for acanthocephalans in 4 nature reserves in 2 Chinese provinces during 20042006. Pseudoacanthocephalus bufonis (Echinorhynchida) occurred in both nature reserves in Guangxi Province. In the Jing Xi County Provincial Nature Reserve, P. bufonis infected 36 of 62 amphibians at a mean intensity of 9.9 . Less than $250 \mathrm{~km}$ away, at Shiwandashan National Nature Reserve, 5 of 20 amphibians were infected at a mean intensity of 6.2. Pseudoacanthocephalus bufonis was not found in either of the reserves in Guizhou Province. In the Kuan Kuoshui Nature Reserve, 9 of 28 amphibians were parasitized at a mean intensity of 2.0 by a previously undescribed species of Pseudoacanthocephalus, and no acanthocephalan occurred in a small sample of 2 toads at Dashahe Nature Reserve. The new species, Pseudoacanthocephalus reesei n. sp., differs from all others in the genus by typically having 14 longitudinal rows of 4 hooks, each of which is much longer than corresponding hooks of any other species of the genus. The length of proboscis hooks increases from the apex to the base of the proboscis, further distinguishing the new species from all but Pseudoacanthocephalus nguyenthileae.
\end{abstract}

Human disturbance threatens natural habitats throughout the world. Nowhere is this fact more evident than in China. Human activities have impacted natural areas in China for thousands of years, yet the biodiversity in southern China is poorly known. The area is heavily populated, and a large proportion of the existing forest is secondary growth (MacKinnon, 1997; Robbins et al., 2006; Boyd et al., 2008). Recently the Chinese provincial governments established reserves to protect remaining fragments of tropical and subtropical evergreen forests. As part of a biotic survey of southern China, we surveyed parasites from terrestrial vertebrates at reserves in Guangxi and Guizhou provinces during the period 2004-2006 (Fig. 1). Here we report the occurrence of acanthocephalans found in these amphibians. Specimens of the 2 species present in the Chinese collection permit an updated description of a long known species and add a previously undescribed species to the known biota of China.

\section{MATERIALS AND METHODS}

\section{Sampling sites}

Jing Xi County Nature Reserve: This reserve, located in Guangxi Province $\left(23.12^{\circ} \mathrm{N}, 105.96^{\circ} \mathrm{E}\right.$, elevation 900 to $\left.1,400 \mathrm{~m}\right)$ was sampled during 2004. The fieldwork was based along a rapid stream that ran through secondary forest at $950 \mathrm{~m}$. There was evidence of old banana cultivations; however, the rugged terrain seemed to protect some of the forest from human disturbance. Ridge top forests were less disturbed, with many large trees (c. 20-30 m high) and a few trees reaching c. $50 \mathrm{~m}$ high

Shiwandashan National Nature Reserve: This reserve, located in Guangxi Province $\left(21.84^{\circ} \mathrm{N}, 107.88^{\circ} \mathrm{E}\right.$, elevation $\left.300-900 \mathrm{~m}\right)$ was sampled during 2005. The fieldwork was based along a winding paved road that ran through the steep mountains of the park. The forest was secondary, with the tallest trees c. $25 \mathrm{~m}$ tall. The slow stream near camp ran rapidly with heavy rains.

Kuan Kuoshui Nature Reserve: This reserve, located in Guizhou Province $\left(28.23^{\circ} \mathrm{N}, 107.16^{\circ} \mathrm{E}\right.$, elevation $\left.1,450-1,750 \mathrm{~m}\right)$ was sampled during 2006. The fieldwork was based at $1,450 \mathrm{~m}$ elevation in deciduous and evergreen forest, with several trees c. $20-25 \mathrm{~m}$ tall. The valley and the base of the surrounding hills were largely cultivated. Mountain streams drained into a small lake in the valley.

Dashahe Nature Reserve: This reserve, located in Guizhou Province $\left(29.17^{\circ} \mathrm{N}, 107.57^{\circ} \mathrm{E}\right.$, elevation $\left.1,350-1,650 \mathrm{~m}\right)$ was sampled during 2006.

Received 22 March 2009; revised 27 April 2009; accepted 26 May 2009.

* Department of Biology, University of New Mexico, Albuquerque, New Mexico 87131.

$\dagger$ School of Biological Sciences, University of Nebraska-Lincoln, Lincoln, Nebraska 68588

DOI: 10.1645/GE-2101.1
The fieldwork was based in an area where the natural vegetation was heavily disturbed. Much of the area was covered with agricultural plots, such as tobacco (Boyd et al., 2008). Scrubby secondary growth surrounded the valley, and some native vegetation lined a small river that ran through the steep karst landscape. The largest trees were only c. $15 \mathrm{~m}$ tall.

\section{Collection of amphibians and worms}

Amphibians were collected opportunistically along trails, streams, pools, and lakes. Most $(>80 \%)$ were killed and necropsied in the field. During these dissections, worms were removed and placed in water at ambient temperature. When their proboscides were everted, worms were transferred to $10 \%$ buffered formalin. The remaining amphibians were partially necropsied in the field. Their intestinal tracts were removed and frozen in liquid nitrogen for later dissection in the laboratory.

\section{Preparation of worms}

Worms were hydrated by passing them through decreasing concentrations of ethanol until they were in distilled water. They were stained in Mayer's carmalum and dehydrated through increasing concentrations of ethanol until they were in absolute ethanol, after which they were cleared in xylene and mounted in Canada balsam on microscope slides. After being stained, several of the male worms were dissected to determine the number and arrangement of their cement glands before being dehydrated and mounted on slides. Measurements are in micrometers unless stated otherwise; widths refer to the widest point of the structure being measured. Numbers in parentheses indicate sample means. Descriptions are based solely on mature specimens, that is, males with secretions in efferent ducts and females with fully formed eggs. Hooks were measured only in full lateral profile, with the length being the straight-line distance from the tip of the thorn to its junction with the root. Proboscis length is the distance from the proximal-most hook to the apex, and neck length is the distance from the root of the proximal-most hook to the tegumental boundary demarcating junction with the trunk. Ecological terminology is as recommended by Bush et al. (1997).

\section{Deposition of voucher and type specimens}

Holotype and allotype specimens of the new species were deposited in the U.S. National Parasite Collection (USNPC), Beltsville, Maryland; paratypes of the new species and voucher specimens of Pseudoacanthocephalus bufonis (Shipley, 1903) Petrochenko, 1956, were deposited in the Harold W. Manter Laboratory collection of the University of Nebraska State Museum (HWML), Lincoln, Nebraska. Host specimens were deposited in the Kansas Museum of Natural History, and in regional museums in China.

\section{RESULTS}

\section{Survey}

During the 3-yr survey, 112 amphibians of 24 species were collected in nature reserves in Guangxi Province and Guizhou 


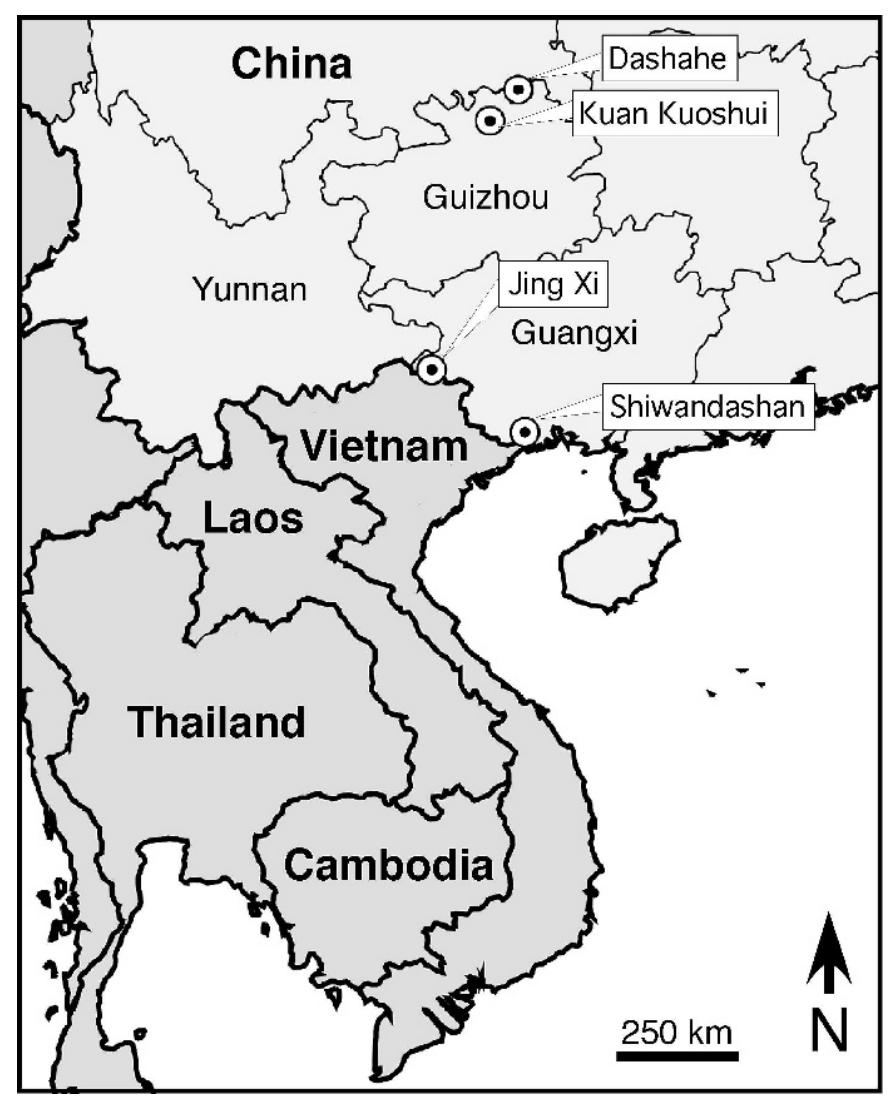

Figure 1. Southeastern Asia, showing 4 sites in the People's Republic of China where amphibians were collected and examined for acanthocephalans. Jing Xi, $2004(\mathrm{n}=62)$; Shiwandashan, $2005(\mathrm{n}=20)$; Kuan Kuoshui, $2006(\mathrm{n}=28)$; and Dashahe, $2006(\mathrm{n}=2)$.

Province, China. Acanthocephalans occurred in 50 (45\%) of the amphibians at a mean intensity of 7.8. Acanthocephalans were most common and intense at the Jing Xi County Provincial Nature Reserve, where they all were $P$. bufonis (Table I). Prevalence and intensity were less at the Shiwandashan National Nature Reserve where, likewise, P. bufonis was the only species collected (Table I). At Kuan Kuoshui Nature Reserve, the prevalence of acanthocephalans was intermediate, but the intensity was low. The only acanthocephalan species collected at this location was the new species we describe here (Table I). At Dashahe Nature Reserve, only 2 specimens were examined; both were Bufo gargarizans, and neither individual harbored acanthocephans.

\section{REDESCRIPTION}

\section{Pseudoacanthocephalus bufonis (Shipley, 1903) Petrochenko, 1956}

(Figs. 2-3)

General: Echinorhynchidae with thick-walled trunk of about uniform diameter in males, wider anteriorly and posteriorly in females. Females much larger than males, 15.3-28.0 (20.9) $\mathrm{mm}$ long by 1.1-2.3 (1.6) $\mathrm{mm}$ wide anteriorly. Males 5.7-11.8 (8.8) $\mathrm{mm}$ long by $1.0-2.2(1.3) \mathrm{mm}$ wide. Proboscis size and armature about the same in both sexes; 408-542 (485) long by 283-360 (324) wide; armed with 16-18 (usually 16) longitudinal rows of 5-6 (usually 5 alternating with 6 ) hooks each. Hooks range between 71 and 104 (85) long among specimens, but about same length from anterior to posterior on proboscis of a given specimen; mean lengths (anterior to posterior): 79, 86, 91, 89, 84, 77. Neck about 240 long by 415 wide at junction with trunk. Short, thick lemnisci frequently obscured by proboscis receptacle and presomal musculature; 0.80-1.42 (1.11) $\mathrm{mm}$ long. Double-walled proboscis receptacle with musculature of irregular contour, 685-950 (874) long by 270-346 (320) wide. Cerebral ganglion at base of proboscis receptacle; 168-251 (227) long by 72-96 (89) wide.

Male: Reproductive system reaches from posterior end to about midlevel of trunk. Two oblong testes neither consistently larger than other, 510-945 (719) long by 288-579 (432) wide. Six filiform cement glands, tightly packed and encircling junction of vasa efferentia and vas deferens, 768-1,507 (1,303) long; arranged in 2 groups of a long, intermediate, and short gland each. Ducts in each triumvirate unite forming cement reservoir; reservoirs join at level of Saefftigen's pouch.

Female: Reproductive system reaches anteriorly about $1.2 \mathrm{~mm}$ from decidedly subterminal genital pore. Uterine bell, inclusive of selector apparatus, 451-678 (567) long by 158-240 (191) wide; uterus 293-384 (352) long; vagina 240-360 (322) long. Eggs fusiform with 4 concentric membranes lacking polar prolongations; 55-72 (59) long by 19-24 (21) wide when measured through body wall; 65-72 (70) long by 19-24 (22) wide when dissected from body.

\section{Taxonomic summary}

Hosts and localities: See Table I.

Site of infection: Small intestine.

Specimens deposited: HWML Nos. 49139, 49140, 49141.

\section{Remarks}

Pseudoacanthocephalus bufonis was described originally by Shipley (1903) from specimens collected in toads from Thailand. Our specimens agree fully with his description except that proboscis hooks were said to be in "6-8 alternating rings." This would be equivalent to $3-4$ hooks in each longitudinal row instead of the 5-6 present in our specimens from China. It is impossible to tell from his illustrations whether the proboscides of Shipley's specimens were evaginated fully, and type specimens are unavailable (Kennedy, 1982) for study. Joyeux and Baer (1935) reported 5-6 hooks in each longitudinal row for this species collected from the type host (Bufo melanostictus Schneider, 1799) at Tonkin, Vietnam. Our specimens agree fully with their description and illustrations, and there is no appreciable difference from the redescription of the species by Kennedy (1982).

There is discrepancy in the literature regarding the date Echinorhynchus bufonis Shipley, 1903, first was assigned to Pseudoacanthocephalus. Among principal compilations of acanthocephalan species, Yamaguti (1963) and Golvan (1994) listed the transfer as 1958, while referencing the genus Pseudoacanthocephalus Petrochenko, 1956. At the first use of the generic name, Pseudoacanthocephalus, Petrochenko (1956) did not define it as a new genus. However, later in the same volume (Petrochenko, 1956), he gave characters for Pseudoacanthocephalus, designated it a new genus, and specifically transferred 4 species to it, including Acanthocephalus bufonis (Shipley, 1903) Southwell and Macfie, 1925.

The nomenclature is further complicated because Kennedy (1982) argued that specimens identified by Petrochenko (1953) as P. bufonis from toads in Turkmenistan and Uzbekistan are not conspecific with the species described by Shipley (1903). Kennedy (1982) proposed the new name Acanthocephalus breviprostatus for the Soviet specimens. As Petrochenko (1956) was referencing these specimens when he assigned $P$. bufonis as the type species, Pseudoacanthocephalus breviprostatus Kennedy, 1982, should replace $P$. bufonis as the type species of Pseudoacanthocephalus for systematists who concur that $P$. bufonis and $P$. breviprostatus constitute distinct species. Because Petrochenko's transfer of Shipley's E. bufonis was an explicit nomenclatural act, even if fortuitous, Amin (1985) properly listed the name as Pseudoacanthocephalus bufonis (Shipley, 1903) Petrochenko, 1956, regardless of its status as type species of the genus.

\section{DESCRIPTION}

\section{Pseudoacanthocephalus reesei $n$. sp.} (Figs. 4-9)

General: Echinorhynchidae with thick walled trunk of about uniform diameter in males, wider anteriorly and posteriorly in females. Females 
TABLE I. Occurrence of acanthocephalans among amphibians sampled in 4 nature reserves in China from 2004 to 2006.

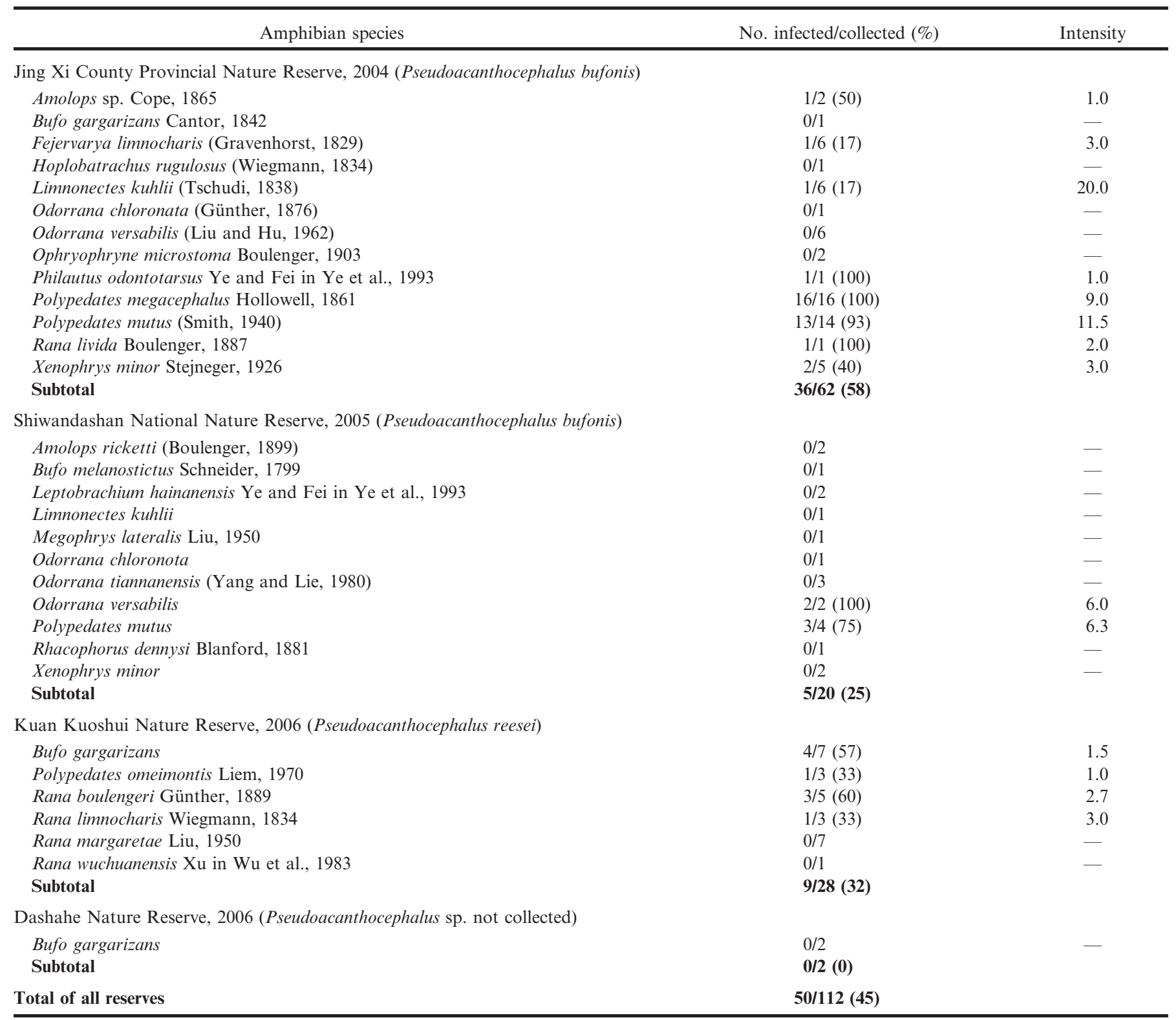

$11.8-14.8$ (13.7) $\mathrm{mm}$ long by $0.8-1.2(1.0) \mathrm{mm}$ wide anteriorly; males 6.0 10.3 (8.7) $\mathrm{mm}$ long by $0.9-1.3(1.1) \mathrm{mm}$ wide. Proboscis size and pattern of hooks about the same in both sexes; 432-490 (461) long by 346-389 (360) wide; armed with 12-15 (usually 14) longitudinal rows of 4-5 (usually 4) hooks each. Hooks increase in size from anterior to posterior; much longer in females (92-139) than in males $(72-120)$. Mean lengths of proboscis hooks (anterior to posterior): 91, 106, 115, 131 in females; 78, 91, 99, 108, 109 in males. Neck 250-396 (380) long by 470-618 (546) wide at junction with trunk. Short, thick lemnisci frequently obscured by proboscis receptacle and presomal musculature; 0.98-1.27 (1.14) mm long. Double walled proboscis receptacle with musculature of irregular contour, 720 1,056 (910) long by 250-336 (308) wide. Cerebral ganglion at base of proboscis receptacle; 192-254 (246) long by 58-67 (62) wide.

Male: Reproductive system reaches from posterior end to about midlevel of trunk. Two oblong testes neither consistently larger than other, 576-691 (617) long by 288-470 (436) wide. Six filiform cement glands, tightly packed and encircling junction of vasa efferentia and vas deferens, 902-1,315 (1,162) long; arranged in 3 groups of a long, intermediate, and short gland each. Ducts in each triumvirate unite forming cement reservoir; reservoirs join at level of Saefftigen's pouch.
Female: Reproductive system reaches anteriorly about $1.7 \mathrm{~mm}$ from decidedly subterminal genital pore. Uterine bell, inclusive of selector apparatus, 557-781 (669) long by 139-168 (154) wide; uterus 528-634 (553) long; vagina 384-451 (418) long. Eggs fusiform with 4 concentric membranes lacking polar prolongations; 84-96 (92) long by 19-24 (22) wide when measured through body wall.

\section{Taxonomic summary}

Type host: Rana boulengeri Gunther, 1889.

Other hosts: See Table I.

Type locality: Kuan Kuoshui Nature Reserve, Guizhou Province, China.

Site of infection: Small intestine.

Specimens deposited: Holotype male, USNPC No. 102010; allotype, USNPC No. 102011; paratypes USNPC No. 102012, 102013, HWML No. 49137, 49138. Holotype ex: Rana boulengeri MCB-503; allotype ex: Polypedates omeimontis MCB-542; paratypes ex: $R$. boulengeri MCB-499, MCB-533. Host specimens deposited at Kansas Museum of Natural History, University of Kansas, Lawrence, Kansas. 


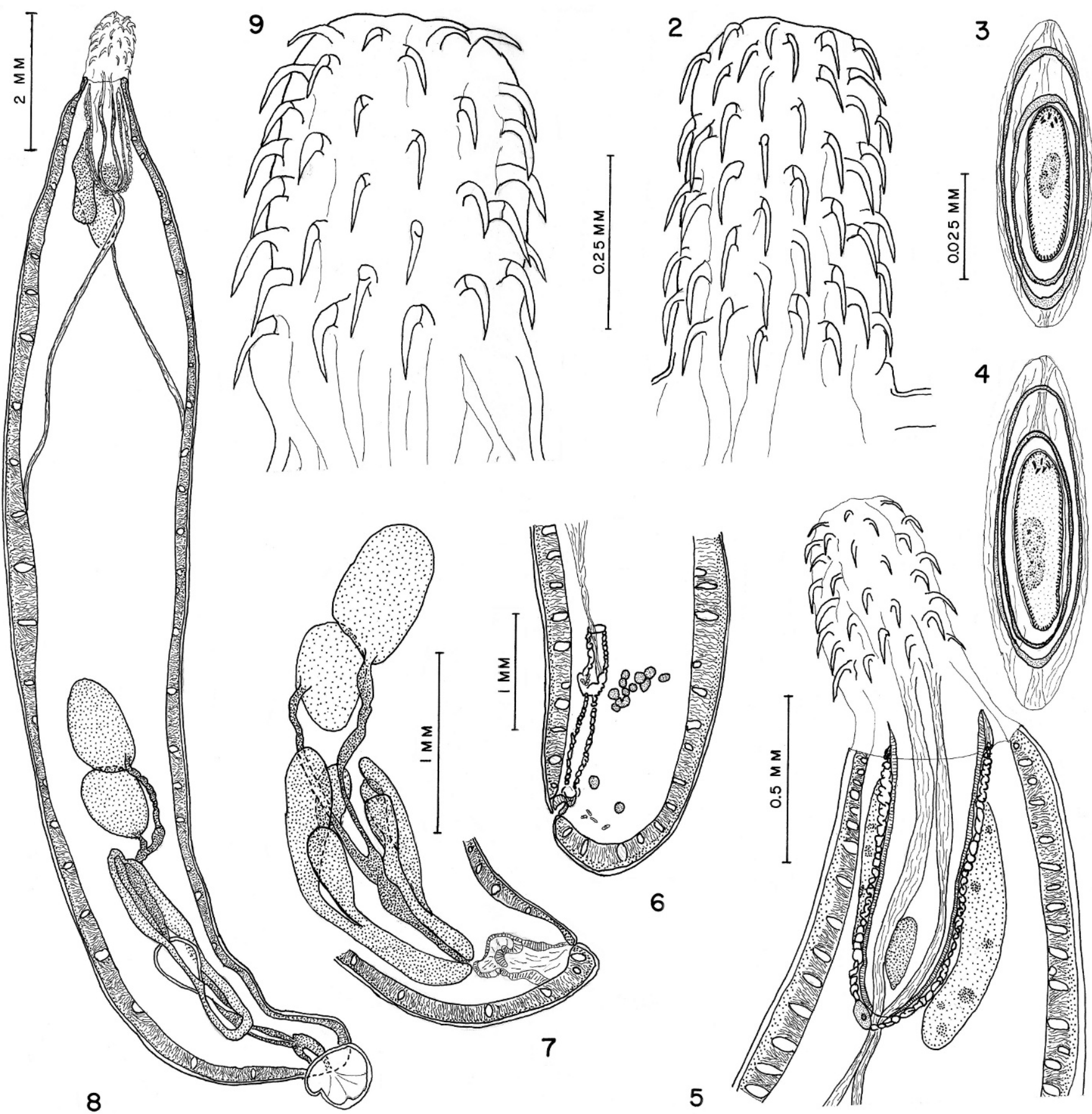

Figures 2-9. Acanthocephalans from amphibians collected in China. Pseudoacanthocephalus bufonis. (2) Proboscis; (3) egg. Pseudoacanthocephalus reesei $\mathrm{n}$. sp. (4) Egg; (5) presoma of male; (6) posterior end of female; (7) teased reproductive system dissected from a male worm; (8) entire male; (9) proboscis. Scale between Figures 2 and 9 applies to both; that beside Figure 3 applies to both Figures 3 and 4 .

Etymology: The species is named in honor of Maxwell Reese, biology teacher at American Fork High School, Utah, in recognition of his inspiration and guidance to young scientists.

\section{Remarks}

The arrangement of proboscis hooks typically in 14 longitudinal rows of 4 hooks each distinguishes $P$. reesei from all other species of the genus except Pseudoacanthocephalus bigueti (Houin, Golvan, and Brygoo, 1965) Golvan, 1969, Pseudoacanthocephalus perthensis Edmonds, 1971, and Pseudoacanthocephalus rhampholeontos Smales, 2005. The hooks of $P$. reesei, however, are much longer than has been reported for these other 3 species and apparently for any other species of the genus. Additionally, $P$. reesei is distinguished because it and Pseudoacanthocephalus nguyenthileae Amin, Ha, and Heckmann, 2008, are the only species of the genus in which proboscis hooks increase progressively in length from anterior to posterior positions. Besides having fewer longitudinal rows of fewer, but longer, hooks than $P$. nguyenthileae, males of $P$. reesei possess the typical 6 cement glands rather than 8 as reported (Amin et al., 2008) for P. nguyenthileae.

Several species currently classified as members of Acanthocephalus Koelreuther, 1771, likely will be reassigned to Pseudoacanthocephalus when more is learned about them. Among these, only Acanthocephalus 
lucidus Van Cleave, 1925, is similar to $P$. reesei. The 2 species are nearly alike except in the length of their eggs and proboscis hooks. Eggs of $P$. reesei are shorter than those of $A$. lucidus (84-96 vs. 94-106), and the hooks are longer. According to Van Cleave (1925), hooks of A. lucidus are "slightly" shorter (70) at the proboscis tip than those more posteriorly (88). The difference is much greater for $P$. reesei, with the mean length being 78 anteriorly and 109 posteriorly in males and 91 anteriorly and 131 posteriorly in females.

Harada (1935) and Yamaguti (1939) described specimens collected from several species of amphibians in Japan and identified them as A. lucidus. Their descriptions of the specimens differ conspicuously from the original description of the species by Van Cleave (1925), and, with respect to trunk size, proboscis armature, and egg size, they are almost identical to $P$. reesei. It is likely that Harada (1935) and Yamaguti (1939) did not recognize their specimens as a new species and misidentified them as $A$. lucidus, which occurs in similar amphibians in the region. Future study is likely to show that the Harada and Yamaguti specimens are, in fact, conspecific with $P$. reesei rather than with $A$. lucidus.

\section{DISCUSSION}

Petrochenko (1956) distinguished his new genus Pseudoacanthocephalus from Acanthocephalus by its possession of holoechinate acanthors, terrestrial hosts, and absence of polar elongations in acanthor membranes. Golvan (1969) added possession of a subterminal genital pore in females as a feature by which the 2 genera differ. Although Golvan (1969) stated that the 2 genera could be differentiated clearly, Schmidt (1971) questioned the validity of these generic characters, and the issue was readdressed by Smales (2005). Golvan (1994) continued to recognize Pseudoacanthocephalus as did Amin et al. (2008), who gave rationale for its validity. In addition to the characters defined by Petrochenko (1956) and Golvan (1969), and the more elongated tightly clustered cement glands (compacted so tightly as to be uncountable in the absence of dissection or cross sections) noted by Amin et al. (2008), the 2 species collected in China appear to differ from Acanthocephalus by possession of a very thick body wall and in having the musculature of the outer wall of the proboscis receptacle arranged in irregular bands rather than the smooth sheath of Acanthocephalus. Species previously assigned (Golvan, 1994; Amin et al., 2008) to Pseudoacanthocephalus and $P$. reesei, described here, constitute a readily recognized group of distinctive species.

Pseudoacanthocephalus bufonis is a long known parasite across southeastern Asia (Shipley, 1903; Joyeux and Baer, 1935; Schmidt, 1971; Uchida, 1975; Jain and Gupta, 1981; Kennedy, 1982; Khan and Ip, 1986; Vashetko and Siddikov, 1999; Bursey et al., 2005) to Hawaii, where it probably was introduced (Barton and Pichelin, 1999). It is not surprising, therefore, that it was abundant in amphibians in our survey in China. The presence of this species in China, however, has not been well documented. Southwell and Macfie (1925) reported 4 specimens from the intestine of a single toad captured in Hong Kong without indicating the host species. Van Cleave (1937) described Acanthocephocephalus sinensis, now widely regarded as a synonym (Amin, 1985; Golvan, 1994) of P. bufonis, based on specimens collected by E. C. Faust in central China during the period from 1920 to 1925. Otherwise there is little previous information published regarding this species in China.

Although amphibians of 6 species were collected at more than 1 field site, insight regarding habitat and host distribution is meager because most of the species were captured at only a single site.
Pseudoacanthocephalus reesei occurred only at the Kuan Kuoshui Reserve, which is at a considerably higher elevation than the reserves where $P$. bufonis occurred. The toads Bufo gararizans Cantor, 1842, were collected at 3 reserves, but were infected only at Kuan Kuoshui; however, only 3 specimens of this species were obtained at reserves other than Kuan Kuoshui.

Gravid specimens of $P$. bufonis occurred only in Polypedates megacephalus Hallowell, 1861, and Polypedates mutus (Smith, 1940), but at the higher elevation of Kuan Kuoshui these amphibian species were not collected. Gravid specimens of $P$. reesei occurred in Polypedates omeimontis Liem, 1970, Rana boulengeri Gunther, 1889, and Rana limnocharis Wiegmann, 1834 , but amphibians of these species were not collected at lower elevations. The single specimen of Rana (Rana livida Boulenger, 1887) collected at lower elevations was parasitized by $P$. bufonis Our survey data imply that in southern China, P. bufonis occurs at lower elevations where the principal hosts are $P$. megacephalus and $P$. mutus. At higher elevations, several amphibian species, primarily $R$. boulengeri, are parasitized by $P$. reesei. Surveys of acanthocephalans at other high elevation sites are necessary to substantiate this assertion.

\section{ACKNOWLEDGMENTS}

We thank Matt Brandley, Rafe Brown, Juan M. Guayasamin, C. J. Hayden, Luis C. Marquez, and Iqbal Setiadi for their efforts collecting and identifying amphibians. We thank Vasyl Tkach for assistance in dissecting frogs. We thank G. Esch for comments on the manuscript. This work was supported by NSF DEB-0344430, Biotic Survey \& Inventories grant to A. Townsend Peterson, Dale H. Clayton, Rafe Brown, and Burton Lim.

\section{LITERATURE CITED}

Amin, O. M. 1985. Classification. In Biology of the Acanthocephala, D W. T. Crompton and B. B. Nickol (eds.). Cambridge University Press, Cambridge, U.K., p. 27-72.

- N. V. Ha, and R. A. Heckmann. 2008. New and already known acanthocephalans from amphibians and reptiles in Vietnam, with keys to species of Pseudoacanthocephalus Petrochenko, 1956 (Echinorhynchidae) and Sphaerechinorhynchus Johnston and Deland, 1929 (Plagiorhynchidae). Journal of Parasitology 94: 181-189.

Barton, D. P., AND S. Pichelin. 1999. Acanthocephalus bufonis (Acanthocephala) from Bufo marinus (Bufonidae: Amphibia) in Hawaii. Parasite 6: 269-272.

Boyd, R. L., A. S. Nyari, B. W. Benz, And G. Chen. 2008. Aves, Province of Guizhou, China. Check List 4: 107-114.

Bursey, C. R., S. R. Goldberg, and F. Kraus. 2005. Endoparasites in Sphenomorphus jobiensis (Sauria: Scincidae) from Papua New Guinea with description of three new species. Journal of Parasitology 91: 1385-1394.

Bush, A. O., K. D. Lafferty, J. M. Lotz, and A. W. Shostak. 1997. Parasitology meets ecology on its own terms: Margolis et al. revisited. Journal of Parasitology 83: 575-583.

Golvan, Y. J. 1969. Systematique des acanthocephales (Acanthocephala Rudolphi, 1801): L'ordre des Palaeacanthocephala Meyer, 1931. I. La super-famille des Echinorhynchoidea (Cobbold, 1876) Golvan et Houin, 1963. Memoires du Museum National d'Histoire Naturelle, nouvelle serie, ser. A, Zoologie 57: 1-373.

1994. Nomenclature of the Acanthocephala. Research and Reviews in Parasitology 54: 135-205.

HaradA, I. 1935. Zur Acanthocephalenfauna von Japan. Memoirs of the Faculty of Science and Agriculture, Taihoku Imperial University 14: $7-23$

JAIN, M., AND N. K. Gupta. 1981. On two species of the genus Acanthocephalus Koelreuther 1771 (Acanthocephala: Echinorhynchidae) including the description of a new species, A. goaensis. Rivista de Parassitologia 42: 163-176. 
Joyeux, C., AND J. G. BAER. 1935. Etude de quelques acanthocephales d' Indochine. Annales du Musee d"Histoire Naturelle de Marseille 27: $1-15$.

Kennedy, M. J. 1982. A redescription of Acanthocephalus bufonis (Shipley, 1903) Southwell and Macfie, 1925 (Acanthocephala: Echinorhynchidae) from the black-spotted toad, Bufo melanostictus, from Bogor, Indonesia. Canadian Journal of Zoology 60: 356-360.

Khan, M. M., AND Y. K. Ip. 1986. Parasites of toads from Singapore, with a description of Balantidium singaporensis sp. n. (Ciliophora: Balantidiidae). Zoological Science 3: 543-546.

MacKinnon, J. 1997. Protected areas systems review of the Indo-Malayan realm. Asian Bureau for Conservation, Canterbury, U.K., 198 p.

Petrochenko, V. I. 1953. Thorny-headed worms (Acanthocephala) of U. S. S. R. amphibians. In Contributions on helminthology in commemoration of the birthday of K. I. Skrjabin, A. M. Petrov (ed.). Academii Nauk S. S. S. R., Moscow, Russia, p. 507-517.

. 1956. Acanthocephala of domestic and wild animals, vol. 1. Izdatel'stvo Akademii Nauk S. S. S. R., Moscow, Russia, 435 p.

Robbins, M. B., A. T. Peterson, A. Nyari, G. Chen, and T. J. Davis. 2006. Ornithological surveys of two reserves in Guangxi Autonomous, China, 2004-2005. Forktail 22: 140-146.

Schmidt, G. D. 1971. Acanthocephalan infections of man, with two new records. Journal of Parasitology 57: 582-584.
ShIPley, A. E. 1903. On the ento-parasites collected by the "Skeat Expedition" to Lower Siam and the Malay Peninsula in the years 1899-1900. Proceedings of the Zoological Society of London 2: 145156.

Smales, L. R. 2005. Acanthocephalans from some frogs and toads (Anura) and chameleons (Squamata) from Tanzania with the description of a new species. Journal of Parasitology 91: 1459-1464.

Southwell, T., AND J. W. S. Macfie. 1925. On a collection of Acanthocephala in the Liverpool School of Tropical Medicine. Annals of Tropical Medicine and Parasitology 19: 141-184.

UCHIDA, A. 1975. Check list of the helminth parasites of Japanese amphibians. Bulletin of the Azabu Veterinary College 30: 63-81.

Van Cleave, H. J. 1925. Acanthocephala from Japan. Parasitology 17: $149-156$.

1937. Acanthocephala from China. II. Two new species of the genus Acanthocephalus from Amphibia. Parasitology 29: 395-398.

VashetKo, E. V., AND B. H. Siddikov. 1999. The effect of the ecology of toads on the distribution of helminths. Tubitak Journal of Zoology 23: $107-110$.

Yamaguti, S. 1939. Studies on the helminth fauna of Japan Part 29. Acanthocephala, II. Japanese Journal of Zoology 8: 317-351.

1963. Systema helminthum, vol. 5. Acanthocephala. Interscience Publications, John Wiley and Sons, New York, New York, 423 p. 